\title{
Gambling Participation in Australia: Findings from the National Household Expenditure Survey
}

\author{
ANDREW WORTHINGTON \\ School of Accounting and Finance, University of Wollongong, Wollongong, NSW 2522, Australia. andreww@uow.edu.au \\ KERRY BROWN \\ School of Management, Queensland University of Technology, GPO Box 2434, Brisbane, QLD 4001, Australia. ka.brown@qut.edu.au \\ MARY CRAWFORD \\ School of Management, Queensland University of Technology, GPO Box 2434, Brisbane, QLD 4001, Australia. m.crawford@qut.edu.au \\ DAVID PICKERNELL \\ Business School, University of Glamorgan, Pontypridd, Wales CF37 1DL, United Kingdom.dgpicker@glam.ac.uk
}

\begin{abstract}
Regression modeling is used to predict gambling patterns in Australia on the basis of the unit record files underlying the Australian Bureau of Statistics’ Household Expenditure Survey of 6,892 households. The four largest categories of gambling expenditure are examined, namely: lottery tickets, lotto-type games and instant lottery (scratch cards), TAB (pari-mutuel wagering) and related on course betting, and poker (slot) machines and ticket machines. Determining factors analyzed include the source and level of household income, family composition and structure, welfare status, gender, age, ethnicity and geographic location. Apart from the determinants of expenditure varying widely across the different types of gambling activity, the results generally indicate that the source of household income is more important than the level of income and that household composition and regional location are likewise significant in determining gambling expenditure.
\end{abstract}

Keywords: gambling expenditure, socioeconomic and demographic characteristics, cross-sectional analysis.

JEL Classification: C31, C35, D12, H22

\section{Introduction}

In size and importance the Australian gambling industry has grown significantly over the last three decades. During this time there has been a fourfold increase in real gambling turnover, now more than $\mathrm{A} \$ 95$ billion, in real gambling expenditure, currently some $\mathrm{A} \$ 821$ per person, and in government revenue, at present accounting for some $\mathrm{A} \$ 3,850$ million in gamblingrelated taxation, or about 10 percent of State government revenues (Productivity Commission, 1999). It is well recognized that all Australian governments have played a major role in this phenomenal growth in the legalization, design and provision of gambling activities. Accordingly, by some measures Australian are among the developed world's most committed gamblers with per capita expenditure exceeding the US, Hong Kong and New Zealand and total expenditure of $\$ 10.8$ billion greater than that spent in Australia on energy or household appliances and approaching alcohol (Productivity Commission, 1999).

\footnotetext{
* The authors would like to thank three anonymous referees and the editor, Shoshana Grossbard, for helpful comments on an earlier version of this paper. The financial assistance of the Queensland Treasury's Responsible Gambling Research Grant Program is also gratefully acknowledged.
} 
Unfortunately, the gambling industry can be accompanied by undesirable socio-economic problems. For example, whilst gambling participation is voluntary, the pattern of expenditure may work to the relative detriment of low-income individuals and deepen the economic problems that must be addressed by other public support programs (Andrew Szakmary and Carol M. Szakmary, 1995; Ranjana Madhusudhan, 1996; Rachel Volberg, 1996; Robert Ladouceur, 1996; Lisa Farrell and Ian Walker, 1999). For instance, there has been a steady increase in the percentage of household disposable income spent on gambling in Australia from less than one percent in the mid-1970s to currently in excess of three percent (Productivity Commission, 1999). A recent survey of household gambling in Queensland identified 0.83 percent of the adult population (or 21,910 persons) as problem gamblers, 2.70 percent $(71,227$ persons) with moderate-risk gambling, and a further 8.18 percent $(215,824$ persons) with low-risk gambling (Gambling Policy Directorate, 2001). Equivalently, a survey by the Productivity Commission (1999) concluded that problem gamblers constituted 15 percent of regular (non-lottery) gamblers, losing on average A\$12,000 per annum as compared to $\$ 650$ for non-problem gamblers. Moreover, persons associated within these groups are very often associated with yet other social problems including alcohol and drug abuse, depression and suicide and losing time from work or study (Gambling Policy Directorate, 2001).

Public policy in Australia has now begun to recognize some of these problems; largely in response to a community backlash against the expansion of gambling opportunities [the survey conducted by the Productivity Commission (1999) indicated that 70 percent of respondents believed gambling did more harm than good and 92 percent opposed the introduction of new gambling venues and machines]. Currently, at least some proportion of tax levies is spent on harm minimization, the treatment of problem gambling and research into the costs and benefits of gambling. Similarly, smoking bans and limits on hours, and the restriction on access to automatic teller machines (ATM) within gambling premises are also representative of a differing approach to policy in this area as are requirements for the display of information about the 'price' and nature of gambling products, the provision of information about the risks of problem gambling, controls on advertising and pre-commitment options, including self-exclusion arrangements (Productivity Commission, 1999).

Nevertheless, there is the ongoing need to address the important question of the socioeconomic burden of gambling expenditure. Mary O. Borg and Paul M. Mason (1988), Mary O. Borg, Paul M. Mason and Stephen L. Shapiro (1991; 1993), Frank Scott and John Garen (1994), J. Ronnie Davis, John E. Filer and Donald L. Moak (1992), Raymond Jackson (1994), 
Ann Hansen (1995), Samuel Cooper and Elchanan Cohn (1994), William M. Rodgers and Charles Stuart (1995), John F. Scoggins (1995), Allan Layton and Andrew Worthington (1999) and Andrew Worthington (2001) are examples of this type of work. More recently, research has focused on a wider interpretation as a means of providing some policy input into the potential for problem gambling and other undesirable consequences of expansion in the gambling industry. Work in this area includes Thomas A. Garrett and Thomas L. Marsh (2002), Paul H. Delfabbro and Anthony H. Winefeld (1999a, 199b), Christian Jacques, Robert Ladouceur and Francine Ferland (2000) and Rodney E. Stanley and P. Edward French (2003).

The purpose of the present paper is to add to this literature the results of an analysis of gambling expenditure by Australian households. The Australian Bureau of Statistics' (ABS) (2002) Household Expenditure Survey (HES) Confidentialised Unit Record File (CURF) is employed for this purpose. This survey focuses on both expenditure decisions by households, as well as the socioeconomic and demographic characteristics of these households. The remainder of the paper is divided into three main areas. The first section explains the empirical methodology and data collection employed in the analysis. The second section discusses the results. The paper ends with some brief concluding remarks.

\section{Research method and data}

The analytical technique employed in the present study is to specify expenditures on various categories of gambling as a censored dependent variable $(y)$ in a Tobit model with socioeconomic and demographic characteristics as explanatory variables $(x)$. This model takes allowance of the fact that a proportion of households usually have zero gambling expenditure: that is, the dependent variable is censored at zero. The variables used to estimate this model are detailed in Table 1. All data are obtained from the Australian Bureau of Statistics' 1998/99 Household Expenditure Survey Confidentialised Unit Record File and relate to a sample of 6,892 probability-weighted Australian households. However, it has two weaknesses when used to analyze gambling data (Productivity Commission, 1999).

First, with the rapid growth in the Australian gambling industry, the data from the Household Expenditure Surveys in 1993/94 and now 1998/99 predate some of the growth of Australian casinos and the expansion of gaming machines in Queensland, South Australia, Victoria and Tasmania. Second, the data may understate the actual level of gambling expenditure in Australia. For example, the Productivity Commission (1999) calculated average gambling expenditure of A\$821 per person, while the survey indicates about $\mathrm{A} \$ 470$. 
Such differences arise for three main reasons. First, the Productivity Commission (1999) figures include gambling by non-residents excluded from the Household Expenditure Survey. Second, there is also a problem with the selective recall of gambling expenditures over the two-week survey period in the survey: some respondents may not recall all gambling undertaken in this period. Finally, large gamblers may not respond accurately or truthfully in the survey.

\section{<TABLE 1 HERE $>$}

In terms of the dependent variables, the four major categories of household weekly gambling expenditure are employed (percentage of sample households engaged in the category of gambling in brackets). These are: lottery tickets (7.5 percent), lotto-type games and instant lotteries (35.8 percent), Totalisor Agency Board betting and related on-course betting (6.2 percent), and poker machines and ticket machines (9.5 percent). The survey also includes expenditure on blackjack, roulette and other casino-type games, other TAB-betting (excluding animal racing), and club and casino broadcast gaming. However, the proportion of households participating in these other forms of gambling is never more than 2.3 percent of the sample. The average weekly dollar expenditures in these categories of gambling are likewise small (less than A $\$ 0.25$ per week per household).

Some details of the selected categories are as follows. First, lottery tickets are one of the oldest forms of state-controlled gambling activities in Australia and are similar to state lotteries in the US. In fact, until the advent of lotto-type games in the 1980s, lotteries were the main form of gambling available to Australians outside horse-racing. Second, lotto-type games, including Lotto and Powerball, are where players choose six winning numbers from forty-five numbered balls drawn in a weekly televised draw. These and instant lotteries (or scratch cards) are similar to games played in the US and are available from newsagents. In the case of lotto-type games, many Australian households engage in this type of regular gambling. Reasons include the very large prizes offered, the fact that participation can be automated to run over a number of successive weeks, and the widespread media attention given to the draws. Instant (or scratch) lotteries are equally popular, and are almost a default gift to include in Christmas and birthday cards.

Third, TAB betting (pari-mutuel wagering undertaken at dedicated shop-front agencies and at networked agencies in pubs, bars and clubs) and related on-course betting (through bookmakers at racetracks) relate to horse and dog racing. This type of betting is popular with Australian males. Finally, poker (or slot) machines and ticket machines are found in most 
pubs, clubs and casinos and often appeal to older females. While pubs and clubs are ubiquitous in Australian towns and suburbs, there is only one or two large casinos in each state (usually in the capital), which offer a mix of gambling and up-market entertainment (i.e. Star City Casino in Sydney, Crown Casino in Melbourne, Treasury Casino in Brisbane and Jupiter’s Casino at the Gold Coast).

Whilst few studies have employed more than a single expenditure classification as the dependent variable, the definitions adopted are consistent with Frank Scott and John Garen's (1994) and Harry Kitchen and Scott Powell's (1991) respective analyses of lotteries in Kentucky and Canada, Stuart E. Thiel's (1991) inquiry into Washington's Lotto, Ann Hansen's (1995) study of Colorado instant lotteries, and Penelope Pugh and Paul Webley's (2000) research into UK lottery participation, amongst others. In terms of average weekly gambling expenditure, lottery tickets are highest (A \$3.43), followed by poker machines and ticket machines (A \$2.14), Totalisor Agency Board betting and related on-course betting (A \$1.47) and lotto-type games and instant lotteries (A \$0.38).

The set of socio-economic and demographic variables upon which the household gambling expenditures are regressed are also included in Table 1 . Whilst there is no unequivocal rationale for predicting the direction and statistical significance of many of these independent variables, their inclusion is consistent with both past studies of gambling-taxation and demographic/socioeconomic incidence and the presumed interests of policy-makers and other parties. However, the effects are expected to vary across the various categories of gambling expenditure. As an example, the Productivity Commission (1999) found that gaming machine players are slightly biased towards middle-income earners and those aged between 18 and 24; racing punters are slightly biased towards males, middle income earners and those aged between 18 and 34; and the profile of lottery gamblers reflects that of the general population with a small bias towards people aged between 50 and 64 and people with higher incomes.

The first four variables relate to household structure. These represent households composed of a single person living alone, a couple with no other usual residents, couples with children and lone parents with children. The reference category is mixed and other families. As a rule, it is usually found that single persons and lone parents with children are overrepresented in most studies of gambling incidence. A positive coefficient is hypothesized when gambling expenditure is regressed against persons living alone and lone parents with children. The next four variables correspond to the gender of the household reference person and their age [see, for instance, Harry Kitchen and Scott Powells (1991) and Penelope Pugh and Paul Webley (2000)]. The reference category are male and persons aged twenty-nine 
years or younger, respectively. All other things being equal, households headed by females generally spend less on gambling than male household heads while many categories of gambling are biased towards participation by younger gamblers, including TAB on-course and related betting; middle-aged gamblers tend to focus on lotteries and lotto type games and instant lotteries; and older gamblers are concentrated in expenditures relating to poker and ticket machines.

The following eight variables all relate to the ethnic background of the household. It is generally observed that different ethnic groups may be focused towards particular types of gambling as against others (Andrew Worthington, 2001). The variables specified include whether the household head (and spouse of the household head) was born in northwest, southern or eastern Europe, North Africa and the Middle East, southeast, north-east, southern and central Asia or the Americas or Sub-Saharan Africa. Finally, four variables are included to reflect additional dimensions of household structure and characteristics. These are: the number of usual residents in the household, the proportion of female spenders in the household, the proportion of dependents in the household and the proportion of retirees in the household. The hypotheses are that households with a higher number of residents are generally associated with larger expenditures on gambling, whereas high proportions of females, dependents and the retired are associated with lower expenditures.

The next group of variables relate to both the level of weekly household income and the sources of this income, and follow the work of Harry Kitchen and Scott Powells (1991) and Penelope Pugh and Paul Webley (2000), amongst others. For the former, the level of expenditure on gambling products is posited to increase with income, though at a diminishing rate. In the case of the latter, Frank Scott and John Garen (1994) and Andrew Worthington (2001) have discussed the purported impact of welfare recipiency on gambling expenditures. It is posited that even after holding household income constant, certain groups of welfare recipients may engage in a disproportionate amount of gambling expenditure. The qualitative (dummy) variables included to test this hypothesis are firstly whether the household in question derives the larger portion of its income from self employment, superannuation, investments and other private income and age, disability, unemployment, education, sickness and other pensions and benefits. A measure of relative socio-economic disadvantage is also included. This index is calculated by the ABS and includes attributes such as low income, low educational attainment, high unemployment and jobs in relatively unskilled occupations, and refers to the area in which a person lives, not to the socioeconomic situation of the particular individual. 
The final set of information comprises several dummy variables reflecting each respondent's regional location: namely, New South Wales, Victoria, Queensland, South Australia, Western Australia and Tasmania. The justification behind these measures is that the characteristics of the gambling industry and its products vary substantially across state borders, largely due to the differing pace of legalization and liberalization of state-regulated gambling. For example, New South Wales has had gaming machines for over 40 years. In contrast, this form of gambling has only relatively recently been introduced in Victoria, South Australia and Queensland while Western Australia has no gaming machines outside of casinos. Moreover, the characteristics of gambling products, and hence the demand for them, vary greatly across the various states and territories. These typically include the price of the product, the size of the prize, the odds of winning, the extent to which odds can be changed by skill, the accessibility of the product, the experiences associated with the venue and the social acceptability of the activity. The signs and significance of the coefficients on regional location will therefore necessarily depend on the interaction between numbers of factors.

\section{Empirical findings}

The estimated coefficients, standard errors and $p$-values of the parameters for the Tobit regressions are provided in Table 2. All standard errors and p-values incorporate Huber/White robust covariances to allow for heteroskedasticity. Also included in Table 2 are F-statistics for the null hypothesis that all the slope coefficients are jointly zero and Akaike Information Criterion, Schwarz Criterion and Hannan-Quinn Criterion as a guide to model selection. To test for multicollinearity, variance inflation factors are calculated (not shown). As a rule of thumb, a factor greater than ten indicates the presence of harmful collinearity. Amongst the explanatory variables, the highest factors are for the number of residents (5.4746), persons living alone (4.8860), the proportion of dependents (4.7912) and couples with children at home (4.5500). This suggests that multicollinearity, while present, is not too much of a problem. The estimated models are all highly significant, with tests of the hypotheses that all of the slope coefficients are zero rejected at the 1 percent level or lower using the F-statistics in Table 2. The results in the models also appear sensible in terms of both the precision of the estimates and the signs on the coefficients.

$<$ TABLE 2 HERE $>$

The first model discussed is that determining gambling expenditure on lottery tickets. The estimated coefficients for persons living along, lone parents with children, persons aged thirty 
to forty-nine years and fifty to sixty-nine years, spouses born in North Africa and the Middle East, and households enumerated in New South Wales, Victoria, Queensland, Western Australia and Tasmania are significant at the 10 percent level of significance or lower. This indicates that persons living alone, lone parents with children and households with a spouse from North Africa or the Middle East expend less on lottery tickets, while households headed by a person aged between 30 and 49 years and 50 and 69 years expend relatively more. In terms of state effects, expenditure is significantly higher in New South Wales and significantly lower in Victoria, Queensland, Western Australia and Tasmania. The largest marginal effects on Australian households' expenditure on lottery tickets, both negative, are whether the person is living at home alone or if the spouse is from North Africa or the Middle East. Unlike findings elsewhere [see, for example, Mary O. Borg, Paul M. Mason and Stephen L. Shapiro (1991), Frank Scott and John Garen (1994) and Harry Kitchen and Scott Powells (1991)] there appears to be no significant influence of gender on this type of gambling.

These results differ greatly to the model for lotto type games and instant (scratch) lotteries. In that regression, the estimated coefficients for persons living alone, couples with and without children, persons in all specified age groups, households with a greater number of residents and with a greater proportion of dependents and retirees, households deriving their income principally from self-employment, superannuation and investments, and pensions and households enumerated in New South Wales, Victoria, Queensland, Western Australia and Tasmania are significant at the .10 level or lower. The results indicate, in addition to that presented for lotteries that households with heads between thirty and forty years, with the major portion of household income sourced from self-employment, investments and superannuation and pensions or with a lower level of relative socioeconomic disadvantage spend proportionately less on lotto and instant lottery type games. Ethnicity of the household head or spouse and the level of income appear to have no effect on expenditure on lotto type games and instant lotteries. The most significant marginal effects are a negative effect from the proportion of household dependents and a positive effect for a household from Western Australia.

For TAB on-course and related betting gambling, expenditure is relatively higher for households with a head aged between 50 and 69 years and more than 70 years and those with a greater proportion of members who are retired. Expenditures are lower for persons living alone, couples and lone parents with children, households with female heads, households with heads born in Asia or a spouse born in Europe or the Americas and Sub-Saharan Africa, or 
with a greater portion of members who are female or dependents. TAB on-course and related betting gambling expenditure is also significantly higher in New South Wales. The greatest marginal effects on TAB on-course and related betting gambling, both negative, are the portion of members who are either female or dependents.

For poker machines expenditures are positively associated with a household head between 50 and 69 years, the number of usual residents and households in New South Wales and negatively associated with household heads from North Africa and the Middle-East, the proportion of dependents, the self-employed, those with pensions as the principal source of household income, and households from Western Australia. As with the models for lotto type games and instant lotteries and TAB on-course betting, households in an area of higher socioeconomic disadvantage are associated with lower levels of gambling expenditure. The most significant impacts on poker machine gambling (both negative) are households with a high proportion of dependents and a household from Western Australia.

\section{Concluding remarks}

The present study uses regression analysis to investigate the determinants and incidence of gambling expenditures in Australian households. The current paper extends empirical work in this area in at least three ways. First, and as far as the authors are aware, it represents the first attempt to test the purported determinants of gambling expenditures across all states in Australia using the latest Household Expenditure Survey. The evidence provided suggests that, on average, participation in manifest gambling activities such as lotteries, Lotto and instant lotteries, TAB and on-course betting, and is strongly influenced by socioeconomics and demographics such as age, ethnicity and household composition. However, these effects vary widely across the types of gambling activity.

Second, the study analyses in detail the posited linkage between expenditures on gambling and implied tax incidence. The results indicate that the incidence of gambling-related taxation is income-neutral; that is, gambling expenditures appear unaffected, either positively or negatively, by changes in income. This is very different to findings elsewhere on the role of income in gambling expenditure. For example, Harry Kitchen and Scott Powell (1994) in Canada and Ann Hansen (1994) both found that income was influential. However, other factors are at play in determining gambling expenditures in Australia. More particularly, rather than the level of income, a more pertinent factor in determining the level of gambling 
expenditure in Australia is the primary source of income, whether salaries and wages, selfemployment, investments and superannuation, and pensions and other government benefits.

Perhaps the most striking influence on gambling expenditure in Australian households is the role of household structure and composition and regional location. In the former case, this says much about the demands of families and the ability to engage in certain types of gambling. For example, couples with children are likely to have higher expenditures in gambling products that can be consumed at home such lottery tickets and lotto type games and instant lotteries than blackjack, roulette and other casino type games, though higher dependency ratios is general are associated with lower levels of expenditure. One factor at play here may be the lack of child-minding facilities at casinos for instance. The other interesting feature is the close link between certain forms of gambling expenditure and regional location. This, of course, bears much relation to the role of the states in legalizing and regulating gambling activity. For example, NSW households spend relatively more on lotteries and poker machines, while Western Australian households are the reverse. This indicates that governments do much to change the pattern of gambling expenditure by modifying both the characteristics of the gambling activities and the goods consumed in common with these activities.

\section{References}

Australian Bureau of Statistics. (2002). 1998-99 Household Expenditure Survey Australia, Confidentialised Unit Record File (CURF) Technical Paper, $2^{\text {nd }}$ ed. ABS cat. No. 6544.0.30.001.

Borg, Mary O., and Mason, Paul M. (1988). “The Budgetary Incidence of a Lottery to Support Education,” National Tax Journal 41, 75-85.

Borg, Mary. O., Mason, Paul. M., and Shapiro, Stephen L. (1991). "The Incidence of Taxes on Casino Gambling: Exploiting the Tired and Poor,” American Journal of Economics and Sociology 50, 323-332.

Borg, Mary O., Mason, Paul. M., and Shapiro, Stephen L. (1993). "The Cross Effects of Lottery Taxes on Alternative State Tax Revenue,” Public Finance Quarterly 21, 123-140.

Cooper, Samuel and Cohn, Elchanan. (1994). "Equity and Efficiency of State Lotteries: Review Essay,” Economics of Education Review 13, 355-362.

Davis, J. Ronnie, Filer, John E., and Moak, Donald L. (1992). "The Lottery as an Alternative Source of State Revenue,” Atlantic Economic Journal 20, 1-10.

Delfabbro, Paul H. and Winefeld, Anthony H. (1999). "Poker Machine Gambling: An Analysis of WithinSession Characteristics,” British Journal of Psychology 90, 425-439.

Delfabbro, Paul H. and Winefeld, Anthony H. (1999). “The Danger of Over-Explanation in Psychological Research: A Reply to Griffiths,” British Journal of Psychology 90, 447-450.

Farrell, Lisa and Walker, Ian. (1999). “The Welfare Effects of Lotto: Evidence from the UK,” Journal of Public Economics 72, 99-120.

Gambling Policy Directorate. (2001). Short Analysis of Queensland and Australian Gambling Statistics, Queensland Government Treasury.

Garrett, Thomas A. and Marsh, Thomas L. (2002). "The Revenue Impacts of Cross-Border Lottery Shopping in the Presence of Spatial Autocorrelation,” Regional Science and Urban Economics 32, 501-519. 
Hansen, Ann. (1995). “The Tax Incidence of the Colorado State Lottery Instant Game,” Public Finance Quarterly 23, 385-398.

Jackson, Raymond. (1994). "Demand for Lottery Products in Massachusetts," The Journal of Consumer Affairs 28, 313-325.

Jacques, Christian, Ladouceur, Robert, and Ferland, Francine. (2000). "Impact of Availability on Gambling: A Longitudinal Study,” Canadian Journal of Psychiatry 45, 810-816.

Kitchen, Harry and Powells, Scott. (1991). "Lottery Expenditures in Canada: A Regional Analysis of Determinants and Incidence,” Applied Economics 23, 1845-1852.

Ladouceur, Robert. (1996). “The Prevalence of Pathological Gambling in Canada,” Journal of Gambling Studies 12, 129-142.

Layton, Allan P. and Worthington, Andrew C. (1999). "The Impact of Socioeconomic Factors on Gambling Expenditure,” International Journal of Social Economics 26, 430-440.

Madhusudhan, Ranjana G. (1996). "Betting on Casino Revenues: Lessons from State Experiences,” National Tax Journal 49, 401-412.

Productivity Commission. (1999). Public Inquiry into the Australian Gambling Industry: Final Report. Productivity Commission: Canberra.

Pugh, Penelope and Webley, Paul. (2000). “Adolescent Participation in the U.K. National Lottery Games,” Journal of Adolescence 23, 1-11.

Rodgers, William M. and Stuart, Charles. (1995). "The Efficiency of a Lottery as a Source of Public Revenue,” Public Finance Quarterly 23, 242-254.

Scoggins, John F. (1995). “The Lotto and Expected Net Revenue,” National Tax Journal 48, 61-70.

Scott, Frank and Garen, John. (1994). "Probability of Purchase, Amount of Purchase, and the Demographic Incidence of the Lottery Tax,” Journal of Public Economics 54, 121-143.

Stanley, Rodney E. and French, P. Edward. (2003). "Can Students Truly Benefit from State Lotteries: A Look at Lottery Expenditures Towards Education in the American States,” Social Science Journal 40, 327-333.

Szakmary, Andrew. and Szakmary, Carol M. (1995). "State Lotteries as a Source of Revenue: A Reexamination,” Southern Economic Journal 61, 1167-1181.

Thiel, Stuart E. (1991). “Policy, Participation and Revenue in Washington State Lotto,” National Tax Journal 44, 225-235.

Volberg, Rachel. (1996) "Prevalence of Problem Gambling in the United States,” Journal of Gambling Studies 12, 111-128.

Worthington, Andrew C. (2001). "Implicit Finance in Gambling Expenditures: Australian Evidence on Socioeconomic and Demographic Tax Incidence,” Public Finance Review 29, 326-342. 
TABLE 1. Dependent and independent variable definitions and descriptive statistics

\begin{tabular}{|c|c|c|}
\hline Variable description & Mean & $\begin{array}{l}\text { Standard } \\
\text { deviation }\end{array}$ \\
\hline \multicolumn{3}{|l|}{ Expenditure on gambling } \\
\hline Lottery tickets & 0.38 & 2.15 \\
\hline Lotto type games and instant lottery (scratch cards) & 3.43 & 7.60 \\
\hline TAB on course betting and related & 1.47 & 12.53 \\
\hline Poker machines and ticket machines & 2.14 & 14.31 \\
\hline \multicolumn{3}{|l|}{ Household structure } \\
\hline Person living alone & 0.22 & 0.41 \\
\hline Couple, no other usual residents & 0.24 & 0.43 \\
\hline Couple with children & 0.34 & 0.47 \\
\hline Lone parent with children & 0.09 & 0.28 \\
\hline Sex of household reference person & 0.39 & 0.48 \\
\hline \multicolumn{3}{|l|}{ Age of household reference person } \\
\hline Thirty to forty-nine years & 0.46 & 0.50 \\
\hline Fifty to sixty-nine years & 0.28 & 0.45 \\
\hline Seventy years or more & 0.12 & 0.32 \\
\hline \multicolumn{3}{|l|}{ Country of birth of the household reference person } \\
\hline North-west, southern and eastern Europe & 0.16 & 0.37 \\
\hline North Africa and Middle East & 0.01 & 0.10 \\
\hline South-east, north-east, southern and central Asia & 0.05 & 0.21 \\
\hline Americas, Sub-Saharan Africa & 0.01 & 0.13 \\
\hline \multicolumn{3}{|l|}{ Country of birth of spouse of the household reference person } \\
\hline North-west, southern and eastern Europe & 0.10 & 0.31 \\
\hline North Africa and Middle East & 0.01 & 0.09 \\
\hline South-east, north-east, southern and central Asia & 0.04 & 0.19 \\
\hline Americas, Sub-Saharan Africa & 0.01 & 0.10 \\
\hline Number of usual residents in the household & 2.64 & 1.39 \\
\hline Proportion of female spenders in the household & 0.44 & 0.29 \\
\hline Proportion of dependents in the household & 0.18 & 0.24 \\
\hline Proportion of retirees in the household & 0.17 & 0.36 \\
\hline Weekly household income from all sources & 0.98 & 0.72 \\
\hline \multicolumn{3}{|l|}{ Principal source of household income } \\
\hline Self employed & 0.06 & 0.24 \\
\hline Superannuation, investments and other private income & 0.07 & 0.25 \\
\hline $\begin{array}{l}\text { Age, disability, unemployment, education, sickness } \\
\text { pensions }\end{array}$ & 0.26 & 0.44 \\
\hline Index of relative socio-economic disadvantage & 4.98 & 3.23 \\
\hline \multicolumn{3}{|l|}{ State/territory of enumeration } \\
\hline New South Wales & 0.29 & 0.45 \\
\hline Victoria & 0.19 & 0.39 \\
\hline Queensland & 0.15 & 0.36 \\
\hline South Australia & 0.08 & 0.27 \\
\hline Western Australia & 0.09 & 0.29 \\
\hline Tasmania & 0.06 & 0.25 \\
\hline
\end{tabular}

Notes: Dependent variables are Australian dollar weekly gambling expenditures on lottery tickets, lotto type games and instant lottery (scratch cards), TAB on course betting and related betting and poker machines and ticket machines. The control for household structure is mixed and other families. The control for sex of the household reference person is male. The control for the age of the household reference person is twenty-nine years or less. The control for the country of birth of the household reference person is Australia and Oceania. The control for the country of birth of the household reference person's spouse is Australia and Oceania. The proportion of female spenders, dependents and retirees in the household is in reference to the number of usual residents. Weekly household income is in thousands of A\$. The control for principal source of household income is salaries and wages. The index of relative socio-economic disadvantage is in deciles ranked from a higher level to a lower level of socioeconomic disadvantage. The control for the state/territory of enumeration is the Australian Capital Territory and the Northern Territory. 
TABLE 2. Estimated regression models

\begin{tabular}{|c|c|c|c|c|c|c|c|c|c|c|c|c|}
\hline \multirow[t]{2}{*}{ Variable } & \multicolumn{3}{|c|}{$\begin{array}{l}\text { Lottery } \\
\text { tickets }\end{array}$} & \multicolumn{3}{|c|}{$\begin{array}{l}\text { Lotto type games and instant } \\
\text { (scratch) lotteries }\end{array}$} & \multicolumn{3}{|c|}{$\begin{array}{l}\text { TAB on-course and related } \\
\text { betting }\end{array}$} & \multicolumn{3}{|c|}{$\begin{array}{c}\text { Poker machines and ticket } \\
\text { machines }\end{array}$} \\
\hline & Coef. & Std. error & $p$-value & Coef. & Std. error & $p$-value & Coef. & Std. error & $p$-value & Coef. & Std. error & $p$-value \\
\hline Constant & -17.05 & 2.29 & 0.00 & -12.88 & 1.80 & 0.00 & -90.37 & 19.68 & 0.00 & -103.25 & 17.30 & 0.00 \\
\hline \multicolumn{13}{|l|}{ Household structure } \\
\hline Person living alone & -5.77 & 1.57 & 0.00 & -4.56 & 1.27 & 0.00 & -27.80 & 8.94 & 0.00 & 0.94 & 7.26 & 0.90 \\
\hline Couple, no other usual residents & -1.11 & 1.20 & 0.36 & 1.68 & 1.03 & 0.10 & -11.19 & 6.87 & 0.10 & 5.84 & 5.65 & 0.30 \\
\hline Couple with children & 0.23 & 1.22 & 0.85 & 3.22 & 1.03 & 0.00 & -1.36 & 6.69 & 0.84 & 2.56 & 5.81 & 0.66 \\
\hline Lone parent with children & -2.79 & 1.71 & 0.10 & 0.93 & 1.39 & 0.51 & -20.59 & 9.55 & 0.03 & 8.98 & 7.20 & 0.21 \\
\hline Sex of household reference person & 0.16 & 0.74 & 0.82 & -0.61 & 0.59 & 0.30 & -7.15 & 4.39 & 0.10 & 2.20 & 3.35 & 0.51 \\
\hline \multicolumn{13}{|l|}{ Age of household reference person } \\
\hline Thirty to forty-nine years & 3.24 & 1.39 & 0.02 & 2.16 & 1.16 & 0.06 & -2.02 & 9.00 & 0.82 & 6.26 & 6.23 & 0.32 \\
\hline Fifty to sixty-nine years & 4.25 & 0.75 & 0.00 & 5.02 & 0.64 & 0.00 & 10.81 & 4.74 & 0.02 & 7.23 & 3.63 & 0.05 \\
\hline Seventy years or more & 0.94 & 0.75 & 0.21 & 3.13 & 0.58 & 0.00 & 9.40 & 4.41 & 0.03 & 2.53 & 3.65 & 0.49 \\
\hline \multicolumn{13}{|l|}{ Country of birth of the household reference person } \\
\hline North-west, southern and eastern Europe & 0.45 & 0.80 & 0.58 & -0.28 & 0.67 & 0.67 & -17.23 & 6.18 & 0.01 & -2.76 & 3.99 & 0.49 \\
\hline North Africa and Middle East & -1.44 & 3.95 & 0.71 & -1.28 & 4.85 & 0.79 & -21.73 & 31.04 & 0.48 & -30.12 & 13.65 & 0.03 \\
\hline South-east, north-east, southern and central Asia & 1.09 & 1.48 & 0.46 & -1.20 & 1.32 & 0.36 & -23.11 & 12.85 & 0.07 & -17.47 & 11.52 & 0.13 \\
\hline Americas, Sub-Saharan Africa & -1.97 & 2.26 & 0.38 & -1.94 & 1.68 & 0.25 & -12.00 & 12.97 & 0.35 & -1.49 & 12.35 & 0.90 \\
\hline \multicolumn{13}{|l|}{ Country of birth of spouse of the household reference person } \\
\hline North-west, southern and eastern Europe & -1.29 & 1.00 & 0.20 & 0.26 & 0.80 & 0.75 & -18.40 & 7.42 & 0.01 & -3.09 & 4.87 & 0.53 \\
\hline North Africa and Middle East & -11.53 & 5.90 & 0.05 & -7.19 & 4.78 & 0.13 & -16.42 & 31.31 & 0.60 & -12.03 & 15.65 & 0.44 \\
\hline South-east, north-east, southern and central Asia & -1.93 & 1.67 & 0.25 & -1.75 & 1.39 & 0.21 & -11.58 & 14.23 & 0.42 & -11.19 & 13.01 & 0.39 \\
\hline Americas, Sub-Saharan Africa & -1.18 & 2.49 & 0.64 & -1.62 & 2.00 & 0.42 & -37.46 & 20.20 & 0.06 & -6.24 & 14.84 & 0.67 \\
\hline Number of usual residents in the household & 0.06 & 0.47 & 0.89 & 1.39 & 0.40 & 0.00 & 0.52 & 3.41 & 0.88 & 10.77 & 2.85 & 0.00 \\
\hline Proportion of female spenders in the household & -1.11 & 1.36 & 0.42 & 0.30 & 1.04 & 0.78 & -32.29 & 9.02 & 0.00 & -0.62 & 6.28 & 0.92 \\
\hline Proportion of dependents in the household & -3.58 & 2.51 & 0.15 & -12.12 & 2.10 & 0.00 & -46.07 & 14.60 & 0.00 & -83.94 & 14.93 & 0.00 \\
\hline Proportion of retirees in the household & 1.26 & 1.25 & 0.31 & 5.43 & 1.10 & 0.00 & 20.85 & 9.08 & 0.02 & 9.05 & 6.20 & 0.14 \\
\hline Weekly household income from all sources & 0.00 & 0.00 & 0.47 & 0.00 & 0.00 & 0.46 & 0.01 & 0.01 & 0.16 & 0.00 & 0.00 & 0.11 \\
\hline \multicolumn{13}{|l|}{ Principal source of household income } \\
\hline Self employed & -0.36 & 1.09 & 0.74 & -3.74 & 0.96 & 0.00 & -11.36 & 8.93 & 0.20 & -14.98 & 6.61 & 0.02 \\
\hline Superannuation, investments and other private income & 0.16 & 1.31 & 0.90 & -3.74 & 1.09 & 0.00 & -10.65 & 8.84 & 0.23 & 0.41 & 7.57 & 0.96 \\
\hline Age, disability, unemployment, education, sickness pensions & 0.06 & 0.95 & 0.95 & -3.78 & 0.76 & 0.00 & -8.73 & 6.83 & 0.20 & -13.61 & 4.44 & 0.00 \\
\hline Index of relative socio-economic disadvantage & 0.06 & 0.11 & 0.59 & -0.36 & 0.08 & 0.00 & -1.72 & 0.64 & 0.01 & -1.85 & 0.58 & 0.00 \\
\hline \multicolumn{13}{|l|}{ State/territory of enumeration } \\
\hline New South Wales & 3.90 & 1.16 & 0.00 & 2.00 & 1.01 & 0.05 & 20.37 & 7.89 & 0.01 & 14.58 & 6.30 & 0.02 \\
\hline Victoria & -6.13 & 1.49 & 0.00 & 4.38 & 1.05 & 0.00 & 12.51 & 8.46 & 0.14 & 8.60 & 5.91 & 0.15 \\
\hline Queensland & -2.23 & 1.32 & 0.09 & 5.79 & 1.05 & 0.00 & 8.68 & 8.27 & 0.29 & 7.62 & 6.05 & 0.21 \\
\hline South Australia & 0.11 & 1.47 & 0.94 & 1.86 & 1.16 & 0.11 & 4.52 & 8.78 & 0.61 & 8.37 & 6.52 & 0.20 \\
\hline Western Australia & -2.65 & 1.53 & 0.08 & 6.93 & 1.12 & 0.00 & 10.67 & 8.93 & 0.23 & -55.33 & 12.32 & 0.00 \\
\hline Tasmania & -5.50 & 1.93 & 0.00 & 2.62 & 1.24 & 0.03 & 3.62 & 9.73 & 0.71 & 4.66 & 7.27 & 0.52 \\
\hline Akaike Information Criteria & 0.91 & - & - & 3.62 & - & - & 0.99 & - & - & 1.41 & - & - \\
\hline Schwarz Criteria & 0.94 & - & - & 3.66 & - & - & 1.02 & - & - & 1.45 & - & - \\
\hline Hannan-Quinn Criteria & 0.92 & - & - & 3.64 & - & - & 1.00 & - & - & 1.42 & - & - \\
\hline$F$-stat & 3.80 & - & 0.00 & 11.19 & - & 0.00 & 2.16 & - & 0.00 & 2.61 & - & 0.00 \\
\hline
\end{tabular}

Notes: $F$-statistic is a redundant variables test that all slope coefficients are jointly zero. 